\title{
KEBIJAKAN SISTEM PEMELIHARAAN MESIN PADA PABRIK KOPI SARIWANGI BUMI MUTIARA
}

\author{
Santi \\ Saharuddin Kaseng \\ Husein Hi. Moh. Saleh \\ Jurusan Manajemen, Fakultas Ekonomi, Universitas Tadulako \\ Email: santi.12@gmail.com
}

\begin{abstract}
This study aims to determine and analyze the engine maintenance performed Sariwangi Earth Pearl Factory Shop and to find out whether the policies implemented have been streamlined. To achieve these objectives, using quantitative methods and mathematical statistics as a tool to help decide the maintenance policies to be taken at a certain time.The results showed that the annual preventive maintenance Rp. 4.200.000, -, while corrective annual fee of Rp. 4.500.000, -. Coffee Factory Sariwangi then implement preventive maintenance can save maintenance cost Rp. 300.000, -.
\end{abstract}

Keywords: Maintenance, Preventive and Corrective

\begin{abstract}
Abstrak
Penelitian ini bertujuan untuk mengetahui dan menganalisis pemeliharaan mesin yang dilakukan Pabrik Kopi Sariwangi Bumi Mutiara serta untuk mengetahui apakah kebijakan yang dilakukan sudah efisien. Untuk mencapai tujuan tersebut, dengan menggunakan metode kuantitatif statistik dan matematik sebagai alat untuk membantu memutuskan kebijakan pemeliharaan yang akan diambil pada suatu jangka waktu tertentu. Hasil penelitian menunjukkan bahwa pemeliharaan preventif pertahunnya sebesar Rp. 4.200.000,-, Sedangkan biaya korektif pertahunnya sebesar Rp. 4.500.000,-. Maka Pabrik Kopi Sariwangi menerapkan pemeliharaan preventif yang dapat menghemat biaya pemeliharaan sebesar Rp. 300.000,-.
\end{abstract}

Kata Kunci: Pemeliharaan, Preventif, dan Korektif

\section{PENDAHULUAN}

Pada era sekarang ini pesatnya perkembangan sektor industri menyebabkan banyak negara berkembang mengarahkan pembangunannya pada sektor ini. Sehubungan dengan hal itu maka peranan dunia usaha sangat diperlukan khususnya yang bergerak pada bidang industri yang nantinya diharapkan dapat menunjang pembangunan.

Salah satu faktor penunjang keberhasilan sektor industri adalah ketersediaan mesin dan peralatan yang memadai. Mesin merupakan fakor produksi yang sangat berpengaruh dalam proses produksi. Oleh karena itu, perusahaan perlu menerapkan perawatan mesin yang terencana agar mesin dapat beroperasi secara maksimal, mengurangi kerusakan mesin dan meningkatkan efisiensi produksi.

Kegiatan perawatan atau pemeliharaan mempunyai peranan penting dalam mendukung beroperasinya suatu sistem secara lancar sesuai yang dikehendaki. Selain itu, kegiatan perawatan juga dapat meminimalkan biaya atau kerugian-kerugian yang ditimbulkan akibat adanya kerusakan mesin. (Asisco, Amar, dan Perdana:2012).

Bumi Mutiara adalah UMKM yang kegiatan produksinya mengolah bahan baku biji kopi menjadi kopi bubuk yang diberi merek Kopi Sariwangi. Bumi Mutiara berdiri sejak tahun 1998. Untuk mendapatkan hasil yang terbaik tentunya mesin harus dalam keadaan yang tidak rusak, maka dari itu pemeliharaan pada mesin produksi kopi harus selalu dijaga agar kopi yang dihasilkan akan memuaskan bagi perusahaan.

Pabrik Kopi Bumi Mutiara memiliki dua unit mesin diesel, merk YANMAR tipe 230 dengan kapasitas 20pk, dan YANMAR tipe 8,5 dengan kapasitas 8pk. Kemudian dua unit mesin 
penggorengan/fet dengan kapasitas $30 \mathrm{Kg} / \mathrm{jam}$, dan satu unit mesin penggiling tipe 37 dengan kapasitas 40Kg/jamnya. Kapasitas dan harga mesin adalah:

Tabel 1 Kapasitas dan Harga Mesin Pabrik Kopi Sariwangi

\begin{tabular}{|c|c|c|c|c|}
\hline Merk dan Tipe & Kapasitas & Tahun Pembelian & Harga Pembelian & Jumlah \\
\hline Diesel Yanmar/230 & $20 \mathrm{pk} / 7 \mathrm{Kg} / \mathrm{jam}$ & 1997 & Rp. 2.650 .000 & 1 unit \\
\hline Diesel Yanmar/8,5 & $8 \mathrm{pk} / 5 \mathrm{Kg} / \mathrm{jam}$ & 2011 & Rp. 9.000 .000 & 1 unit \\
\hline Mesin Penggoreng & $30 \mathrm{Kg} / \mathrm{jam}$ & 1997 & Rp. 1.500 .000 & 2 unit \\
\hline Mesin Penggiling & $40 \mathrm{Kg} / \mathrm{jam}$ & 1997 & Rp. 1.200 .000 & 1 unit \\
\hline
\end{tabular}

Sumber: Pabrik Kopi Sariwangi

Kurangnya pemeliharaan mesin dalam suatu perusahaan akan dapat menimbulkan kerusakankerusakan mesin yang cukup fatal, namun karena hal tersebut baru akan dirasakan pada kemudian hari maka perusahaan pada umumnya baru akan mengetahui atau merasakannya apabila mesin produksi yang dipergunakannya telah benar-benar rusak atau tidak dapat dipergunakan secara normal. Adapun mesin yang dimiliki Pabrik Kopi Sariwangi yang mengalami kerusakan, serta biaya pemeliharaannya adalah:

Tabel 2 Mesin yang Mengalami Kerusakan Tahun 2015

\begin{tabular}{|c|c|l|l|}
\hline Jenis Mesin & Jumlah & \multicolumn{1}{|c|}{ Jenis Kerusakan } & \multicolumn{1}{c|}{ Biaya } \\
\hline Diesel & 1 unit & Penggantian gigi pengaturan 1 set & Rp. 1.200.000,- \\
Yanmar/230 & & Penggantian klep 1 set & Rp. 200.000,- \\
& & Penggantian stand saringan & Rp. 300.000,- \\
& & Penggantian knalpot & Rp. 300.000,- \\
\hline Diesel & \multirow{2}{*}{1 unit } & Penggantian puli & Rp. 500.000,- \\
Yanmar/8,5 & & Penggantian tangki & Rp. 250.000,- \\
& & Penggantian radiator & Rp. 400.000,- \\
\hline \multicolumn{2}{|c|}{ Total } & Rp. 3.150.000,- \\
\hline
\end{tabular}

Sumber: Pabrik Kopi Sariwangi (Lampiran 1)

Assauri (1999), menyatakan bahwa, perawatan adalah kegiatan untuk memelihara atau menjaga fasilitas peralatan pabrik dan mengadakan perbaikan atau penggantian yang memuaskan sesuai dengan apa yang direncanakan.

Hasil wawancara terhadap pemilik Pabrik Kopi Sariwangi Bapak Yosep Monoarfa sejak maret 2016 bahwa Pabrik Kopi Sariwangi memiliki jadwal khusus dalam melakukan kegiatan pemeliharaan pengecekan mesin diesel yang dilakukan tiap dua minggu sekali dan terkadang sebulan sekali yang meliputi: penggantian oli, pembersihan filter oli, pembersihan filter udara, dan pembersihan filter solar. Akan tetapi, tahap kegiatan proses produksi yang tiba-tiba memberikan hasil yang tidak layak yang mengharuskan perusahaan untuk melakukan perbaikan atau penggantian komponen mesin-mesin yang rusak.

Berdasarkan latar belakang di atas maka peneliti mendapatkan rumusan masalah yaitu "apakah kebijakan sistem pemeliharaan mesin pada Pabrik Kopi Sariwangi Bumi Mutiara sudah efisien?", serta maksud dan tujuan yang ingin dicapai dalam penelitian ini adalah "untuk mengetahui dan menganalisis pemeliharaan mesin yang dilakukan dan efisiensi biaya yang digunakan untuk pemeliharaan mesin oleh Pabrik Kopi Sariwangi Bumi Mutiara". 


\section{KAJIAN LITERATUR DAN PENGEMBANGAN HIPOTESIS}

\section{Pengertian Manajemen Produksi dan Manajemen Operasi}

Pengertian manajemen produksi dan operasi menurut Handoko (2000:3) merupakan usaha-usaha pengelolaan secara optimal penggunaan sumber daya-sumber daya (atau sering disebut faktor-faktor produksi) tenaga kerja, mesin-mesin, peralatan, bahan mentah dan sebagainya.

Herjanto (2008:2) mengemukakan "pengertian manajemen produksi dan operasi tidak terlepas dari manajemen pada umunya, yaitu mengandung unsur adanya kegiatan yang dilakukan dengan mengkoordinasikan sebagai kegiatan dan sumber daya untuk mencapai suatu tujuan tertentu".

Sedangkan pengertian manajemen operasi menurut Chase Aquilano Jacobs (2001:6), Operations management is defined as the design, operation, and improvement of the system that created and deliver the firm's primary products and services. Artinya adalah manajemen operasi didefinisikan sebagai desain, operasi, dan peningkatan sistem yang menciptkan dan mendistribusikan produk dan jasa perusahaan.

\section{Pengertian Pemeliharaan}

Menurut Assauri (1980:88), "pemeliharaan adalah kegiatan untuk memelihara atau menjaga fasilitas atau peralatan pabrik dan mengadakan perbaikan atau penyesuaian, penggantian yang diperlukan agar supaya terdapat suatu keadaan operasi produksi yang memuaskan sesuai dengan apa yang direncanakan".

Maksud dari pengertian di atas adalah dengan adanya kegiatan pemeliharaan maka peralatan atau fasilitas pabrik dapat digunakan untuk produksi sesuai dengan rencana, dan tidak mengalami kerusakan selama peralatan atau fasilitas tersebut dipergunakan untuk proses produksi atau sebelum jangka waktu tertentu yang direncanakan tercapai.

\section{Tujuan Utama Fungsi Pemeliharaan}

Menurut Daryus, (2008) dalam bukunya Manajemen Pemeliharaan Mesin tujuan pemeliharaan yang utama dapat di definisikan sebagai berikut:

1. Untuk memperpanjang kegunaan aset.

2. Untuk menjamin ketersediaan optimum peralatan yang dipasang untuk produksi dan mendapatkan laba investasi maksimum yang mungkin.

3. Untuk menjamin kesiapan operasional dari seluruh peralatan yang diperlukan dalam keadaan darurat setiap waktu.

4. Untuk menjamin keselamatan orang yang menggunakan sarana tersebut.

\section{Jenis-Jenis Pemeliharaan}

Assauri (2008:135) membagi jenis pemeliharaan menjadi dua yaitu:

\section{Preventive Maintenance}

Yang dimaksudkan dengan preventive maintenance adalah kegiatan pemeliharaan dan perawatan yang dilakukan untuk mencegah timbulnya kerusakan-kerusakan yang tidak terduga dan menemukan kondisi atau keadaan yang dapat menyebabkan fasilitas produksi mengalami kerusakan pada waktu digunakan dalam proses produksi.

Dalam praktinya preventive maintenance yang dilakukan oleh suatu perusahaan dapat dibedakan menjadi dua yaitu:

a. Routine maintenance, adalah kegiatan pemeliharaan dan perawatan yang dilakukan secara rutin misalnya setiap hari.

b. Periodic maintenance, kegiatan pemeliharaan dan perawatan yang dilakukan secara berkala atau dalam jangka waktu tertentu 


\section{Corrective atau breakdown maintenance}

Kegiatan pemeliharaan dan perawatan ini dilakukan setelah terjadinya suatu kerusakan atau kelainan pada fasilitas atau peralatan sehingga tidak dapat berfungsi dengan baik. Kegiatan corrective maintenance yang dilakukan sering disebut dengan kegiatan perbaikan atau reparasi.

\section{Sistem dan Peran Pemeliharaan}

Pengembangan suatu strategi pemeliharaan melibatkan suatu rangkaian keputusan struktural antara lain (1) Aset apa yang harus dipelihara, (2) bagaimana atau atas dasar apa aset harus dipelihara, (3) kapan atau seberapa sering aset harus dipelihara, (4) siapa yang harus mengerjakan dan keterampilan apa yang dibutuhkan. (Jhons dan Handing, 1996:157).

\section{Strategi Pemeliharaan Mesin}

Menurut Suyadi (2007:331) strategi perawatan dapat dibagi menjadi berikut ini:

a. Strategi perawatan berencana

b. Strategi perawatan pencegahan

c. Strategi perawatan peramalan

d. Strategi perawatan darurat

e. Strategi pengukuran kerja para tenaga perawat mesin

\section{Menyusun Rencana Pemeliharaan Secara Sistematis}

Menurut Suyadi (2007:332) tentang penyusunan rencana pemeliharaan secara sistematis dapat dibagi sebagai berikut:

a. Merencanakan pemeliharaan yang efektif

b. Perintah kerja (working order)

c. Melaksanakan perawatan/pemeliharaan

\section{Jadwal dan Program Pemeliharaan Mesin}

Prawirosentono (2007:333) menjelaskan jadwal dan program pemeliharaan mesin yaitu sebagai berikut:

a. Jadwal Perawatan

Jadwal perawatan merupaka pengaturan waktu kegiatan perawatan mesin yang berkaitan dengan kegiatan proses produksi. Dalam perusahaan yang berskala produksi besar dimana banyak mesin produksi yang perlu dipelihara maka tiap kegiatan perawatan yang rinci dan efektif. b. Program Pemeliharaan

Program pemeliharaan (maintenance program) merupakan daftar alokasi kegiatan perawatan mesin yang berisi jadwal waktu pelaksanaan kegiatan perawatan dan alokasi petugas. Program perawatan tersebut dibuat setiap minggu, atau setiap bulan, atau periode waktu tertentu sesuai dengan kebutuhan produksi.

\section{Kerangka Pikir}

Untuk memberikan dasar pemikiran mengenai sistem pemeliharaan mesin dalan hubungannya dengan peningkatan kinerja perusahaan, berikut di gambarkan kerangka pikir penelitian sebagai berikut: 


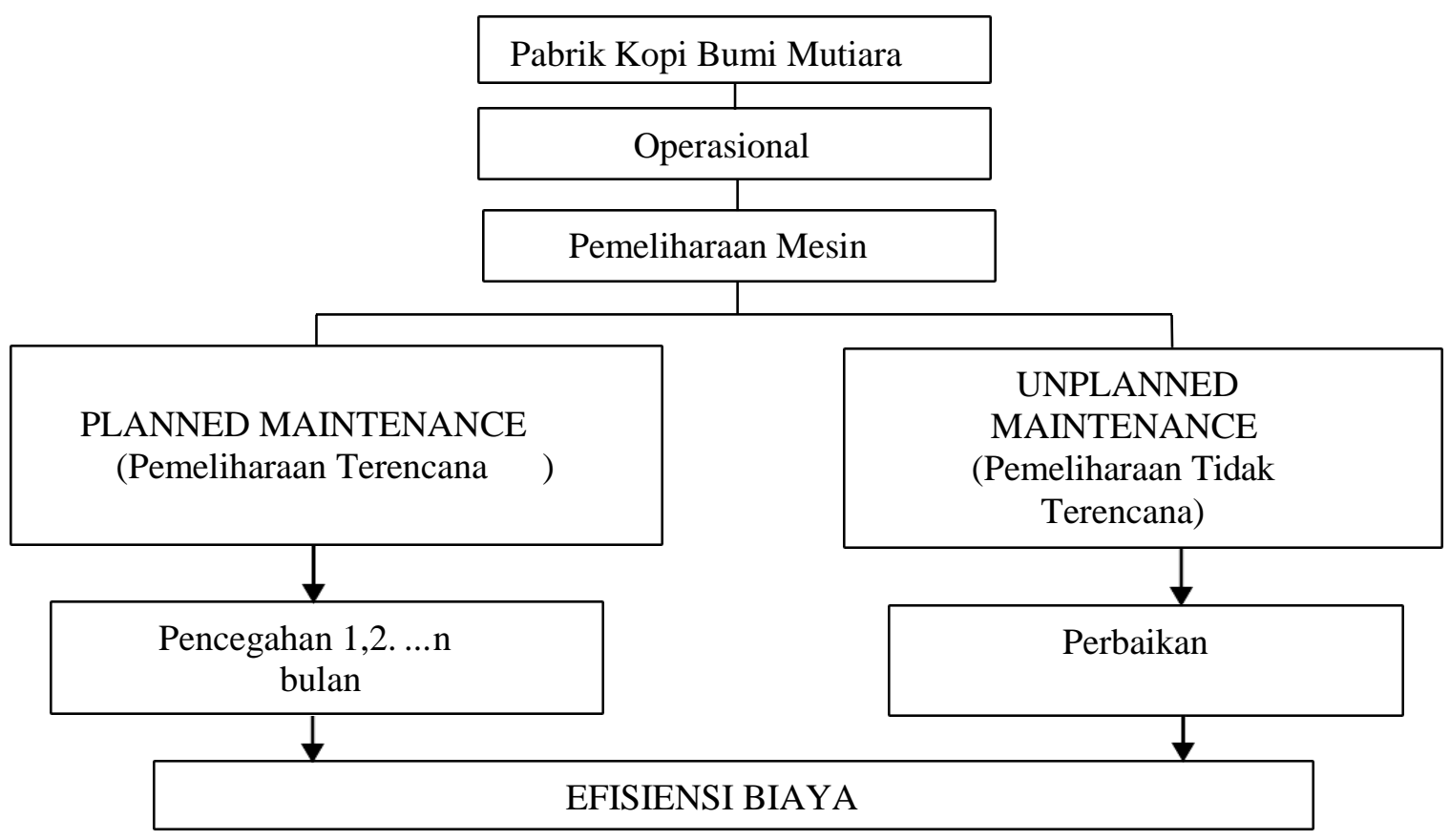

Gambar 1 Kerangka Pemikiran

\section{METODE PENELITIAN}

Penelitian ini merupakan jenis penelitian studi kasus yaitu penelitian yang dilakukan secara intensif, terinci dan mendalam terhadap objek suatu organisme, lembaga atau gejala-gejala tertentu yang diteliti, (Arikunto, 2002:115). Penelitian ini dilakukan di Pabrik Kopi Sariwangi Bumi Mutiara yang terletak di lingkungan industri kecil, Kelurahan Tondo, Kecamatan Mantikulore, Kota Palu, Sulawesi Tengah. Lokasi penelitian ini dipilih dengan alasan peneliti ingin mengetahui apakah dengan melakukan pemeliharaan perencanaan Pabrik Kopi Sariwangi Bumi Mutiara dapat mengefisienkan biaya. Adapun jenis data yang digunakan dalam penelitian ini adalah sebagai berikut:

a. Data kualitatif, yaitu data yang tidak terukur berupa tulisan-tulisan atau keterangan-keterangan dan gambaran-gambaran yang menjelaskan tentang hal-hal yang berhubungan dengan penelitian ini dan masalah yang dibahas.

b. Data kuantitatif, yaitu data terukur berupa angka-angka, jumlah maupun hasil perhitungan yang diperoleh langsung dari perusahaan yang akan diolah lebih lanjut secara sistematis.

Selanjutnya sumber data terbagi atas:

a. Data Primer

Data primer adalah data yang dikumpulkan peneliti langsung dari sumber utamanya (Kountur, 2007:182). Data primer dalam penelitian ini berupa biaya yang dikeluarkan oleh perusahaan dalam melakukan pemeliharaan mesin.

b. Data Sekunder

Data sekunder adalah data yang bersumber dari hasil penelitian orang lain yang dibuat untuk maksud yang berbeda (Kountur, 2007:179). Data sekunder dalam penelitian ini berupa penelitianpenelitian terdahulu dan hasil penelitian kepustakaan.

Teknik pengumpulan data merupakan langkah paling strategis dalam penelitian, karena tujuan utama dari penelitian ini adalah mendapatkan data. Pengumpulan data dapat dilakukan dengan berbagai setting, berbagai sumber, dan berbagai cara, (Sugiyono, 2008:62). Untuk mendapatkan datadata yang dibutuhkan dalam penelitian ini, peneliti menempuh beberapa metode: 
1. Metode Observasi

2. Metode Interview (wawancara)

3. Metode Dokumentasi

Definisi variabel dalam hal ini mencakup mengenai variabel yang telah dipilih ataupun bahan yang digunakan dalam proses produksi yang mencakup mengenai pengertian juga dalam hal ini merupakan batasan yang digunakan untuk mempermudah pengumpulan data dan memperjelas ruang lingkup penelitian yaitu:

1) Pemeliharaan

Dalam hal ini mesin yang harus dipelihara adalah mesin pendukung di Pabrik Kopi Sariwangi Bumi Mutiara, yaitu:

Tabel 3 Jumlah Mesin Pada Pabrik Kopi Sariwangi Bumi Mutiara Yang Mengalami Kerusakan

\begin{tabular}{|c|c|l|c|c|}
\hline Jenis Mesin & Jumlah & \multicolumn{1}{|c|}{ Jenis Kerusakan } & keterangan & Biaya \\
\hline $\begin{array}{c}\text { Mesin Diesel } \\
\text { Yanmar/230 }\end{array}$ & 1 unit & $\begin{array}{l}\text { Penggantian Gigi Pengaturan } \\
\text { 1 set } \\
\text { Penggantian Klep 1 set } \\
\end{array}$ & $\begin{array}{l}\text { P Kali } \\
\text { Kenggantian Stand Saringan } \\
\text { Penggantian Knalpot }\end{array}$ & Rp. 2.000.000,- \\
\hline $\begin{array}{c}\text { Mesin Diesel } \\
\text { Yanmar/8,5 }\end{array}$ & 1 unit & $\begin{array}{l}\text { Penggantian Puli } \\
\text { Penggantian Tangki } \\
\text { Penggantian Radiator }\end{array}$ & $\begin{array}{l}\text { 2 Kali } \\
\text { Kerusakan }\end{array}$ & Rp. 1.150.000,- \\
\hline Total & & & & Rp. 3.150 .000 \\
\hline
\end{tabular}

Sumber: Pabrik Kopi Sariwangi (Lampiran 1)

2) Pemeliharaan Pencegahan

Dalam hal ini mesin yang harus dicegah kerusakannya adalah mesin pendukung di Pabrik Kopi Sariwangi Bumi Mutiara yaitu:

Tabel 4 Jenis dan Jumlah Mesin Yang Mengalami Kerusakan

\begin{tabular}{|l|l|l|c|}
\hline Jenis Mesin & Jumlah (unit) & Jenis Kerusakan & Total Kerusakan \\
\hline Diesel Yanmar & 2 unit & Penggantian Gigi & 5 \\
& & Pengaturan 1 set & \\
& & Penggantian Klep 1 set & \\
& & Penggantian Stand & \\
& & Saringan & \\
& & Penggantian Knalpot & \\
& & Penggantian Puli & \\
& & Penggantian Tangki & \\
& & Penggantian Radiator & \\
\hline
\end{tabular}

Sumber: Pabrik Kopi Sariwangi (Lampiran 1)

3) Pemeliharaan Perbaikan

Mesin pada Pabrik Kopi Sariwangi sangatlah sering digunakan bahkan hampir setiap hari selalu beroperasi, sehingga pemeliharaannya tidak teratur hingga akhirnya mesin tersebut memerlukan perbaikan.

4) Efisiensi Biaya

Digunakan untuk melihat kebijakan pemeliharaan yang telah mencapai efisiensi biaya pemeliharaan yaitu: Biaya pemeliharaan yang digunakan adalah biaya sebelum dilakukan perhitungan kebijakan pemeliharaan, dan biaya pemeliharaan setelah perhitungan adalah biaya setelah menggunakan kebijakan pemeliharaan. 


\section{Metode Analisis}

\section{Metode Kuantitatif}

Metode kuantitatif adalah suatu bentuk analisis data dengan menggunakan statistik dan matematik sebagai alat untuk memperoleh sistem pemeliharaan, untuk membantu memutuskan kebijakan pemeliharaan yang akan diambil pada suatu jangka waktu tertentu oleh Handoko (2000:162) merumuskan:

a. Pemeliharaan pencegahan selama 12 bulan:

1. Pemeliharaan pencegahan setiap sebulan sekali, B1= NP1

2. Pemeliharaan pencegahan dua bulan sekali, $\mathrm{B} 2=\mathrm{N}(\mathrm{P} 1+\mathrm{P} 2)+\mathrm{B} 1 \mathrm{P} 1$

3. Pencegahan tiga bulan sekali,

$$
\mathrm{B} 3=\mathrm{N}(\mathrm{P} 1+\mathrm{P} 2+\mathrm{P} 3)+\mathrm{B} 2 \mathrm{P} 1+\mathrm{B} 1 \mathrm{P} 2
$$

4. Pencegahan empat bulan sekali,

$$
\mathrm{B} 4=\mathrm{N}(\mathrm{P} 1+\mathrm{P} 2+\mathrm{P} 3+\mathrm{P} 4)+\mathrm{B} 3 \mathrm{P} 1+\mathrm{B} 2 \mathrm{P} 2+\mathrm{B} 1 \mathrm{P} 3
$$

5. Pencegahan lima bulan sekali,

$$
\mathrm{B} 5=\mathrm{N}(\mathrm{P} 1+\ldots .+\mathrm{P} 5)+\mathrm{B} 4 \mathrm{P} 1+\mathrm{B} 3 \mathrm{P} 2+\mathrm{B} 2 \mathrm{P} 3+\mathrm{B} 1 \mathrm{P} 4
$$

6. Pencegahan enam bulan sekali,

$$
\mathrm{B} 6=\mathrm{N}(\mathrm{P} 1+\ldots .+\mathrm{P} 6)+\mathrm{B} 5 \mathrm{P} 1+\mathrm{B} 4 \mathrm{P} 2+\mathrm{B} 3 \mathrm{P} 3+\mathrm{B} 2 \mathrm{P} 4+\mathrm{B} 1 \mathrm{P} 5
$$

7. Pencegahan tujuh bulan sekali,

$$
\mathrm{B} 7=\mathrm{N}(\mathrm{P} 1+\ldots .+\mathrm{P} 7)+\mathrm{B} 6 \mathrm{P} 1+\mathrm{B} 5 \mathrm{P} 2+\mathrm{B} 4 \mathrm{P} 3+\mathrm{B} 3 \mathrm{P} 4+\mathrm{B} 2 \mathrm{P} 5+\mathrm{B} 1 \mathrm{P} 6
$$

8. Pencegahan delapan bulan sekali,

$$
\mathrm{B} 8=\mathrm{N}(\mathrm{P} 1+\ldots .+\mathrm{P} 8)+\mathrm{B} 7 \mathrm{P} 2+\mathrm{B} 6 \mathrm{P} 2+\mathrm{B} 5 \mathrm{P} 3+\mathrm{B} 4 \mathrm{P} 4+\mathrm{B} 3 \mathrm{P} 5+\mathrm{B} 2 \mathrm{P} 6+\mathrm{B} 1 \mathrm{P} 7
$$

9. Pencegahan sembilan bulann sekali,

$$
\mathrm{B} 9=\mathrm{N}(\mathrm{P} 1+\ldots .+\mathrm{P} 9)+\mathrm{B} 8 \mathrm{P} 1+\mathrm{B} 7 \mathrm{P} 2+\mathrm{B} 6 \mathrm{P} 3+\mathrm{B} 5 \mathrm{P} 4+\mathrm{B} 4 \mathrm{P} 5+\mathrm{B} 3 \mathrm{P} 6+\mathrm{B} 2 \mathrm{P} 7+\mathrm{B} 1 \mathrm{P} 8
$$

10.Pencegahan sepuluh bulan sekali,

$$
\mathrm{B} 10=\mathrm{N}(\mathrm{P} 1+\ldots . .+\mathrm{P} 10)+\mathrm{B} 9 \mathrm{P} 1+\mathrm{B} 8 \mathrm{P} 2+\mathrm{B} 7 \mathrm{P} 3+\mathrm{B} 6 \mathrm{P} 4+\mathrm{B} 5 \mathrm{P} 5+\mathrm{B} 4 \mathrm{P} 6+\mathrm{B} 3 \mathrm{P} 7+\mathrm{B} 2 \mathrm{P} 8+
$$
B1P9

11.Pencegahan sebelas bulan sekali,

$$
\begin{aligned}
& \mathrm{B} 11=\mathrm{N}(\mathrm{P} 1+\ldots .+\mathrm{P} 11)+\mathrm{B} 10 \mathrm{P} 1+\mathrm{B} 9 \mathrm{P} 2+\mathrm{B} 8 \mathrm{P} 3+\mathrm{B} 7 \mathrm{P} 4+\mathrm{B} 6 \mathrm{P} 5+\mathrm{B} 5 \mathrm{P} 6+\mathrm{B} 4 \mathrm{P} 7+\mathrm{B} 3 \mathrm{P} 8+ \\
& \mathrm{B} 2 \mathrm{P} 9+\mathrm{B} 1 \mathrm{P} 10
\end{aligned}
$$

12.Pencegahan dua belas bulan sekali,

$$
\begin{aligned}
& \mathrm{B} 12=\mathrm{N}(\mathrm{P} 1+\ldots .+\mathrm{P} 12)+\mathrm{B} 11 \mathrm{P} 1+\mathrm{B} 10 \mathrm{P} 2+\mathrm{B} 9 \mathrm{P} 3+\mathrm{B} 8 \mathrm{P} 4+\mathrm{B} 7 \mathrm{P} 5+\mathrm{B} 6 \mathrm{P} 6+\mathrm{B} 5 \mathrm{P} 7+\mathrm{B} 4 \mathrm{P} 8+ \\
& \mathrm{B} 3 \mathrm{P} 9+\mathrm{B} 2 \mathrm{P} 10+\mathrm{B} 1 \mathrm{P} 11
\end{aligned}
$$

b. Pemeliharaan perbaikan

$$
C=\frac{(\mathbf{F})(\mathbf{R 1})}{\mathbf{R 0} . \mathbf{P}}
$$

Dimana:

$\mathrm{C}=$ Biaya perbulan pemeliharaan

$\mathrm{Bn}=$ Ekspektasi jumlah kerusakan mesin dalam $\mathrm{n}$ bulan

$\mathrm{N}=$ Jumlah mesin dalam kelompok

$\mathrm{Pn}=$ Probabilitas mesin rusak dalam periode $\mathrm{n}$

$\mathrm{F}=$ Banyaknya fasilitas

$\mathrm{R} 1=$ Biaya perbaikan

$\mathrm{R} 0=$ Periode antar kerusakan

$\mathrm{P}=$ Probabilitas rusak 


\section{HASIL DAN PEMBAHASAN}

\section{Hasil Penelitian}

Dari hasil penelitian yang dilakukan sejak maret 2016 diketahui bahwa Pabrik Kopi Sariwangi Bumi Mutiara yang beralamat di Lingkungan Industri Kecil, Kawasan Bumi Rofiga, Kelurahan Tondo, Kota Palu, Sulawesi Tengah berdiri sejak tahun 1998 memiliki Mesin Diesel sebanyak dua unit dengan merk YANMAR yang berkapasitas 20 PK, YANMAR dengan kapasitas 8 PK, dua unit mesin penggoreng dengan kapasitas $30 \mathrm{Kg} / \mathrm{jam}$, satu unit mesin penggiling dengan kapasitas $40 \mathrm{Kg} / \mathrm{jam}$. Berikut adalah mesin yang mengalami kerusakan selama tahun 2015 dan total kerusakannya:

Tabel 5 Jumlah Mesin Yang Mengalami Kerusakan Dan Total Kerusakan Tahun 2015

\begin{tabular}{|c|c|c|l|}
\hline Jenis Mesin & $\begin{array}{l}\text { Jumlah Peralatan yang } \\
\text { Mengalami Kerusakan }\end{array}$ & Total Kerusakan & \multicolumn{1}{|c|}{ Jenis Kerusakan } \\
\hline Diesel Yanmar/230 & 1 Unit & 3 Kali & $\begin{array}{l}\text { Penggantian gigi } \\
\text { pengaturan 1 set } \\
\text { Penggantian klep 1 set } \\
\text { Penggantian stand } \\
\text { saringan } \\
\text { Penggantian knalpot }\end{array}$ \\
\hline Diesel Yanmar/8,5 & 1 Unit & 2 Kali & $\begin{array}{l}\text { Penggantian puli } \\
\text { Penggantian tangki } \\
\text { Penggantian radiator }\end{array}$ \\
\hline
\end{tabular}

Sumber: Pabrik Kopi Sariwangi Bumi Mutiara (Lampiran 1)

\section{Sistem Pemeliharaan di Pabrik Kopi Sariwangi Bumi Mutiara}

Sistem pemeliharaan di Pabrik Kopi Sariwangi Bumi Mutiara ini memiliki jadwal khusus dalam melakukan kegiatan pemeliharaan pengecekan mesin diesel yang dilakukan tiap dua minggu sekali dan terkadang sebulan sekali yang meliputi: penggantian oli, pembersihan filter oli, pembersihan filter udara dan pembersihan filter solar. Akan tetapi, tahap kegiatan proses produksi yang tiba-tiba memberikan hasil yang tidak layak yang mengharuskan Pabrik tersebut melakukan perbaikan atau penggantian komponen mesin-mesin yang rusak.

\section{Analisis Sistem Pemeliharaan}

Berikut adalah data mengenai kerusakan mesin tahun 2015 berdasarkan probabilitas:

Tabel 6 Periode Kerusakan Mesin Berdasarkan Probabilitas

\begin{tabular}{|c|c|c|c|}
\hline Periode & Total Kerusakan & Probabilitas (\%) & Probabilitas (\%) Kumulatif \\
\hline 1 & - & - & 0 \\
\hline 2 & - & - & 0 \\
\hline 3 & 2 & 0,4 & 0,4 \\
\hline 4 & - & - & 0,6 \\
\hline 5 & 1 & 0,2 & 0,6 \\
\hline 6 & - & - & 0,6 \\
\hline 7 & - & - & 0,6 \\
\hline 8 & - & - & 0,8 \\
\hline 9 & 1 & 0,2 & 0,8 \\
\hline 10 & - & - & 0,8 \\
\hline 11 & - & - & 1 \\
\hline 12 & 1 & 0,2 & \\
\hline Jumlah & 5 & 1 & \\
\hline
\end{tabular}

Sumber: Data Setelah Diolah 
Pada tabel ini total kerusakan terbanyak terjadi pada bulan ke-3 yaitu 2 kali kerusakan. Pada bulan yang lain total kerusakannya hanya 1 kali kerusakan. Sementara itu biaya pemeliharaan berdasarkan data yang telah diberikan oleh pihak Pabrik Kopi Sariwangi adalah sebagai berikut:

Tabel 7 Biaya kerusakan Tahun 2015

\begin{tabular}{|c|c|l|c|}
\hline Jenis Mesin & Jumlah (unit) & Jenis Kerusakan & Biaya kerusakan/Tahun \\
\hline Mesin Diesel & 2 unit & -Penggantian gigi pengaturan 1 & Rp. 15.750.000,- \\
& & set & \\
& & -Penggantian klep 1 set & \\
& & -Penggantian stand saringan & \\
& & -Penggantian knalpot & \\
& & -Penggantian puli & \\
& & -Penggantian tangki & \\
& & -Penggantian radiator & \\
\hline
\end{tabular}

Sumber: Pabrik Kopi Sariwangi (Lampiran 1)

Hasil di bawah ini merupakan hasil perhitungan probabilitas kerusakan mesin berdasarkan rumus pemeliharaan preventif (Handoko:163):

\section{MESIN DIESEL}

1. Jumlah kerusakan yang diperkirakan, bila pemeliharaan pencegahan dilakukan sebulan sekali: $\mathrm{B} 1=2(0)=0$

2. Jumlah kerusakan yang diperkirakan, bila pemeliharaan pencegahan dilakukan dua bulan sekali: $\mathrm{B} 2=2(0+0)+0=0$

3. Jumlah kerusakan yang diperkirakan, bila pemeliharaan pencegahan dilakukan tiga bulan sekali: $\mathrm{B} 3=2(0+0+0,4)+0(0)+0(0)$ $=0,8$ mesin diesel

4. Jumlah kerusakan yang diperkirakan, bila pemeliharaan pencegahan dilakukan empat bulan sekali:

$\mathrm{B} 4=2(0+0+0,4+0)+0,8(0)+0(0)+0(0,4)$

$=0,8$ mesin diesel

5. Jumlah kerusakan yang diperkirakan, bila pemeliharaan pencegahan dilakukan lima bulan sekali:

$\mathrm{B} 5=2(0+0+0,4+0+0,2)+0,8(0)+0,8(0)+0(0,4)+0(0)=$ 1,2 mesin diesel

6. Jumlah kerusakan yang diperkirakan, bila pemeliharaan pencegahan dilakukan enam bulan sekali:

B6 $=2(0+0+0,4+0+0,2+0)+1,2(0)+0,8(0)+0,8(0,4)+0(0)+0(0,2)=$ 1,52 mesin diesel

7. Jumlah kerusakan yang diperkirakan, bila pemeliharaan pencegahan dilakukan tujuh bulan sekali:

$\mathrm{B} 7=2(0+0+0,4+0+0,2+0+0)+1,52(0)+1,2(0)+0,8(0,4)+0,8(0)+0(0,2)+0(0)$ $=1,52$ mesin diesel

8. Jumlah kerusakan yang diperkirakan, bila pemeliharaan pencegahan dilakukan delapan bulan sekali:

$\mathrm{B} 8=2(0+0+0,4+0+0,2+0+0+0)+1,52(0)+1,52(0)+1,2(0,4)+0,8(0)+0,8(0,2)+$ $0(0)+0(0)$

$=1,84$ mesin diesel

9. Jumlah kerusakan yang diperkirakan, bila pemeliharaan pencegahan dilakukan sembilan bulan sekali: 
B9 $=2(0+0+0,4+0+0,2+0+0+0+0,2)+1,84(0)+1,52(0)+1,52(0,4)+0,2(0)+0,8$ $(0,2)+0,8(0)+0(0)+0(0)$

$=2,368$ mesin diesel

10.Jumlah kerusakan yang diperkirakan, bila pemeliharaan pencegahan dilakukan sepuluh bulan sekali:

$\mathrm{B} 10=2(0+0+0,4+0+0,2+0+0+0+0,2+0)+2,368(0)+1,84(0)+1,52(0,4)+1,52$

$(0)+1,2(0,2)+0,8(0)+0,8(0)+0(0)+0(0,2)$

$=2,808$ mesin diesel

11.Jumlah kerusakan yang diperkirakan, bila pemeliharaan pencegahan dilakukan sebelas bulan sekali:

$\mathrm{B} 11=2(0+0+0,4+0+0,2+0+0+0+0,2+0+0)+2,808(0)+2,368(0)+1,84(0,4)+$ $1,52(0)+1,52(0,2)+0,2(0)+0,8(0)+0,8(0)+0(0,2)+0(0)=2,64$ mesin diesel

12.Jumlah kerusakan yang diperkirakan, bila pemeliharaan pencegahan dilakukan dua belas bulan sekali:

$\mathrm{B} 12=2(0+0+0,4+0+0,2+0+0+0+0,2+0+0+0,2)+2,64(0)+2,808(0)+2,368$

$(0,4)+1,84(0)+1,52(0,2)+1,52(0)+0,12(0)+0,8(0)+0,8(0,2)+0(0)+0(0)=3,4112$ mesin diesel

Perhitungan mengenai keseluruhan ekspektasi kerusakan mesin tiap n bulan, rata-rata kerusakan perbulan, biaya perbaikan kerusakan mesin perbulan, biaya pemeliharaan terencana (preventif) perbulan dan total biaya pemeliharaan perbulan dapat dilihat pada Tabel di bawah ini:

Tabel 8 Perhitungan Biaya Pemeliharaan Preventif Untuk Dua Belas Periode Pemeliharaan Yang Berbeda Pada Mesin Diesel

\begin{tabular}{|c|c|c|c|c|c|}
\hline $\begin{array}{c}\text { (a) } \\
\begin{array}{c}\text { Pemeliharaan } \\
\text { preventif tiap } \\
\text { n-bulan }\end{array}\end{array}$ & $\begin{array}{c}\text { Jumlah } \\
\text { kerusakan } \\
\text { yang } \\
\text { diperkirak an } \\
\text { dalam n-bulan }\end{array}$ & $\begin{array}{c}\text { Jumlah } \\
\text { ratarata } \\
\text { kerusakan } \\
\text { perbulan }\end{array}$ & $\begin{array}{c}\text { Ekspektasi biaya } \\
\text { kerusakan yang } \\
\text { diperkirakan } \\
\text { perbulan }\end{array}$ & $\begin{array}{c}\text { (e) } \\
\text { Biaya } \\
\text { pemeliharaan } \\
\text { yang } \\
\text { diperkirakan } \\
\text { perbulan }\end{array}$ & $\begin{array}{c}\text { (f) } \\
\text { Biaya sub } \\
\text { kebijakan } \\
\text { pemeliharaan } \\
\text { preventif yanbg } \\
\text { diperkirakan }\end{array}$ \\
\hline 1 & & $(\mathrm{c})=(\mathrm{b}) /(\mathrm{a})$ & $\begin{array}{c}\text { (d)=(c)xRp } \\
3.150 .000\end{array}$ & $\begin{array}{c}(\mathrm{e})=(1 / \mathrm{a}) \times \mathrm{xp} \\
700.000 \times 2\end{array}$ & $(\mathrm{f})=(\mathrm{d})+(\mathrm{e})$ \\
\hline 2 & 0 & 0 & 0 & 1.400 .000 & 1.400 .000 \\
\hline 3 & 0 & 0 & 0 & 700.000 & 700.000 \\
\hline 4 & 0,8 & 0,266 & 837.900 & 466.666 & 1.304 .566 \\
\hline 5 & 1,2 & 0,24 & 756.000 & 280.000 & 1.036 .000 \\
\hline 6 & 1,52 & 0,253 & 796.950 & 233.333 & 1.030 .283 \\
\hline 7 & 1,52 & 0,217 & 683.550 & 200.000 & 883.550 \\
\hline 8 & 1,84 & 0,23 & 724.500 & 175.000 & 889.500 \\
\hline 9 & 2,368 & 0,263 & 828.450 & 155.555 & 984.005 \\
\hline 10 & 2,808 & 0,2808 & 884.520 & 140.000 & 1.024 .520 \\
\hline 11 & 2,64 & 0,24 & 756.000 & 127.272 & 883.272 \\
\hline 12 & 3,4112 & 0,284 & 894.600 & 116.666 & 1.011 .266 \\
\hline
\end{tabular}

\section{Sumber: Data Setelah Diolah}

Pada Tabel di atas, dapat diketahui bahwa total biaya pemeliharaan yang paling rendah (minimum) terjadi pada bulan ke dua yakni Rp. 700.000,-. Jadi pemeliharaan pencegahan dapat dilakukan dua bulan sekali. Maka biaya pemeliharaan pertahunnya sebesar Rp. 4.200.000,- 
Tabel 9 Perhitungan Untuk Mencari Jumlah Bulan Yang Diperkirakan Antara Kerusakan

\begin{tabular}{|c|c|c|}
\hline $\begin{array}{c}(\text { a) } \\
\text { Probabilitas terjadinya } \\
\text { kerusakan }\end{array}$ & Periode antar kerusakan & $(\mathrm{a}) \mathrm{x}(\mathrm{b})$ \\
\hline- & - & - \\
\hline- & - & - \\
\hline 0,4 & 2 & - \\
\hline- & - & 0,2 \\
\hline 0,2 & 1 & - \\
\hline 0 & - & - \\
\hline 0 & - & - \\
\hline 0 & - & -2 \\
\hline 0,2 & 1 & - \\
\hline- & - & 0,2 \\
\hline- & - & 1,4 \\
\hline 0,2 & 1 & \\
\hline Jumlah & & \\
\hline
\end{tabular}

Sumber: Data Setelah Diolah

Biaya total pemeliharaan perbaikan (korektif) pertahun untuk mesin diesel adalah:

$$
=\frac{(2 \times \text { Rp. 3.150.000, }-)}{1,4}=\text { Rp.4.500.00,- }
$$

Berdasarkan perhitungan di atas dapat dilihat bahwa untuk pemeliharaan mesin diesel dengan melaksanakan pemeliharaan preventif lebih menghemat biaya dibandingkan dengan pemeliharaan perbaikan. Dimana pemeliharaan preventif pertahun sebesar Rp. 4.200.000,-.., sedangkan untuk biaya perbaikannya sebesar Rp. 4.500.000,-. Untuk mengetahui secara rinci dapat dilihat pada Tabel berikut ini:

Tabel 10

Perbandingan Biaya Kerusakan Dengan Biaya Pemeliharaan Untuk Mesin Diesel Tahun 2015

\begin{tabular}{|c|c|c|c|}
\hline Jenis Mesin & Biaya Kerusakan/Tahun & Biaya Pemeliharaan/tahun & Selisih \\
\hline Diesel Yanmar & Rp. 4.500.000,- & Rp. 4.200.000,- & Rp. 300.000,- \\
\hline
\end{tabular}

Sumber: Data Setelah Diolah

\section{Pembahasan}

Berdasarkan hasil penelitian yang dilakukan sejak maret 2016 Pabrik Kopi Sariwangi memiliki 5 unit mesin yang membantu dalam kegiatan produksi. mesin-mesin tersebut terdiri dari: 2 unit mesin diesel, 2 unit mesin penggoreng dan 1 unit mesin penggiling. Akan tetapi, mesin yang mengalami kerusakan adalah mesin diesel yang jumlah kerusakannya sebanyak 5 kali kerusakan pada tahun 2015.

Pabrik Kopi Sariwangi Bumi Mutiara di Kota Palu memiliki jadwal khusus dalam melakukan kegiatan pemeliharaan pengecekan mesin diesel atau pemeliharaan berkala yang dilakukan tiap 2 minggu sekali dan terkadang sebulan sekali. Dimana pemeliharaan yang dilakukan tiap bulan meliputi: penggantian oli, pembersihan filter oli, pembersihan filter udara dan pembersihan filter solar. Sedangkan pemeliharaan berkala untuk 2 minggu sekali meliputi: pembersihan filter udara dan pembersihan filter solar. Akan tetapi tahap kegiatan proses produksi yang tiba-tiba memberikan hasil yang tidak layak yang mengharuskan Pabrik Kopi Sariwangi untuk melakukan perbaikan atau penggantian komponen mesinmesin yang rusak. Dan hasil yang didapatkan berdasarkan tingkat probabilitas mesin rusak diketahui bahwa secara berturut-turut probabilitas mesin rusak secara kumulatif adalah $0 ; 0 ; 0,8 ; 0,8 ; 1,2 ; 1,52 ; 1,52 ; 1,84 ; 2,368 ; 2,808 ; 2,64 ; 3,4112$. 
Berdasarkan analisa biaya pemeliharaan preventif diketahui bahwa jika pemeliharaan dilakukan sebulan sekali maka biaya yang dikeluarkan sebesar Rp. 1.400.000,-. Jika pemeliharaan dilakukan dua bulan sekali maka biaya yang dikeluarkan sebesar Rp.700.000,-. Jika pemeliharaan dilakukan tiga bulan sekali maka biaya yang dikeluarkan sebesar Rp. 1.304.566,-.Jika pemeliharaan dilakukan empat bulan sekali maka biaya yang dikeluarkan sebesar Rp. 980.000,-. Jika pemeliharaan dilakukan lima bulan sekali maka biaya yang dikeluarkan sebesar Rp. 1.036.000,-. Jika pemeliharaan dilakukan enam bulan sekali maka biaya yang dikeluarkan sebesar Rp. 1.030.283,-. Jika pemeliharaan dilakukan tujuh bulan sekali maka biaya yang dikeluarkan sebesar Rp. 883.550,-. Jika pemeliharaan dilakukan delapan bulan sekali maka biaya pemeliharaan yang dikeluarkan sebesar Rp. 899.500,-. Jika pemeliharaan dilakukan Sembilan bulan sekali maka biaya yang dikeluarkan sebesar Rp. 984.005,-. Jika pemeliharaan dilakukan sepuluh bulan sekali maka biaya yang dikeluarkan sebesar Rp. 1.024.520,-. Jika pemeliharaan dilakukan sebelas bulan sekali maka biaya pemeliharaan yang dikeluarkan sebesar Rp. 883.272,-. Jika pemeliharaan dilakukan dua belas bulan sekali maka biaya yang dikeluarkan sebesar Rp. 1.011.266,-. Maka biaya pemeliharaan preventif terendah pada tahun 2015 jatuh pada bulan ke-2 yaitu sebesar Rp. 700.000,-. Maka pemeliharaan preventif dapat di lakukan 2 bulan sekali yang mana jika pemeliharaan pertahunnya sebesar Rp. 4.200.000,- , sedangkan untuk biaya pemeliharaan perbaikan yaitu sebesar Rp. 4.500.000,- tiap tahunnya, Maka kebijakan pemeliharaan preventif dapat diterapkan di Pabrik Kopi Sariwangi karena dapat menghemat biaya pemeliharaan sebesar Rp. 300.000,-.

\section{KESIMPULAN DAN SARAN}

\section{Kesimpulan}

1. Berdasarkan hasil penelitian diketahui bahwa sistem pemeliharaan yang dilaksanakan oleh Pabrik Kopi Sariwangi adalah kegiatan pemeliharaan berkala yang dilakukan satu bulan sekali dan dua minggu sekali dengan probabilitas kumulatif mesin rusak berturut-turut adalah $0 ; 0 ; 0,8 ; 0,8 ; 1,2$; 1,$52 ; 1,52 ; 1,84 ; 2,368 ; 2,808 ; 2,64 ; 3,4112$.

2. Dari hasil penelitian diketahui bahwa pemeliharaan preventif lebih menghemat biaya pemeliharaan dibandingkan pemeliharaan perbaikan. Biaya pemeliharaan preventif pertahun yaitu sebesar Rp. 4.200.000,-. Sedangkan biaya pemeliharaan perbaikan dalam 1 tahun sebesar Rp. 54.000.000,-.

\section{Saran}

1. Pabrik Kopi Sariwangi sebaiknya menghilangkan pemeliharaan berkala dua minggu sekali dan di gantikan dengan pemeliharaan preventif dua bulan sekali.

2. Diharapkan kepada pihak Pabrik Kopi Sariwangi sebaiknya agar menerapkan kebijakan pemeliharaan preventif, agar dapat menghemat biaya pemeliharaan.

\section{REFERENSI}

Arikunto, S, 2002. Prosedur Penelitian, suatu pendekatan praktek. PT. Rineka Cipta. Jakarta

Assauri, Sofyan. 1980. Manajemen Produksi dan Operasi. Jakarta. LBFE UI

Assauri. Sofyan. 1999. Manajemen Produksi dan Operasi. Edisi Revisi, LPFE-UI, Jakarta

Assauri, Sofyan. 2008. Manajemen Produksi Dan Operasi. Lembaga Penerbit Fakultas Ekonomi

Universitas Indonesia Jakarta

Asisco, Amar, dan Perdana (2012). Usulan Perencanaan Perawatan Mesin Dengan Metode Reliability

Centered Maintenance (RCM) di PT. Perkebunan Nusantara VII (Persero) Unit Usaha Sungai

Niru Kab. Muara Enim. Kaunia, Vol VIII, No 2, Halaman 78-98

Daryus, A. 2008. Proses Produksi. Jakarta: Universitas Darma Persada

Eddy, Herjanto. 2008. Manajemen Operasi. Jakarta: Grasindo

Handoko, Hani. 2000. Dasar-Dasar Manajemen Produksi, edisi pertama, Badan Penerbit Fakultas

Ekonomi, Yogyakarta

Jhons dan Harding (penyuntingan). 1996. Manajemen Operasi. Lembaga PPM. Jakarta Pusat

Kountur, Ronny, 2007. Metode Penelitian (untuk penulisan skripsi dan tesis), perpustakaan Nasional:

Katalog dalam Terbitan (KDT), Jakarta

Sugiyono.2008. Metode Penelitian Kuantitatif dan Kualitatif. CV. Alfabeta :Bandung

Suyadi, Prawirosentono. 2007. Manajemen Operasi (Analisis Studi Kasus), edisi keempat, Bumi Aksara. 